\title{
Review Article \\ Bioceramic-Based Root Canal Sealers: A Review
}

\author{
Afaf AL-Haddad and Zeti A. Che Ab Aziz \\ Department of Restorative Dentistry, Faculty of Dentistry, University of Malaya, 50603 Kuala Lumpur, Malaysia \\ Correspondence should be addressed to Afaf AL-Haddad; afaf_haddad3@yahoo.com
}

Received 27 November 2015; Accepted 6 April 2016

Academic Editor: Traian V. Chirila

Copyright (C) 2016 A. AL-Haddad and Z. A. Che Ab Aziz. This is an open access article distributed under the Creative Commons Attribution License, which permits unrestricted use, distribution, and reproduction in any medium, provided the original work is properly cited.

\begin{abstract}
Bioceramic-based root canal sealers are considered to be an advantageous technology in endodontics. The aim of this review was to consider laboratory experiments and clinical studies of these sealers. An extensive search of the endodontic literature was made to identify publications related to bioceramic-based root canal sealers. The outcome of laboratory and clinical studies on the biological and physical properties of bioceramic-based sealers along with comparative studies with other sealers was assessed. Several studies were evaluated covering different properties of bioceramic-based sealers including physical properties, biocompatibility, sealing ability, adhesion, solubility, and antibacterial efficacy. Bioceramic-based sealers were found to be biocompatible and comparable to other commercial sealers. The clinical outcomes associated with the use of bioceramic-based root canal sealers are not established in the literature.
\end{abstract}

\section{Introduction}

The main functions of root canal sealers are (i) sealing off of voids, patent accessory canals, and multiple foramina, (ii) forming a bond between the core of the filling material and the root canal wall, and (iii) acting as a lubricant while facilitating the placement of the filling core and entombing any remaining bacteria [1]. Due to the relative biological and technical importance of sealers, their chemical and physical properties have been the subject of considerable attention since their initial development in the early twentieth century [2]. Sealers are categorised according to their main chemical constituents: zinc oxide eugenol, calcium hydroxide, glass ionomer, silicone, resin, and bioceramic-based sealers.

Root canal sealers have been reviewed across a number of studies, either collectively [2] or based on their composition, including zinc oxide eugenol [3], calcium hydroxide [4], glass ionomer [5], and resin-based sealers [6]. However, no extensive review of bioceramic-based sealers has been conducted.

Bioceramic-based sealers have only been available for use in endodontics for the past thirty years, their rise to prominence corresponding to the increased use of bioceramic technology in the fields of medicine and dentistry. Bioceramics are ceramic materials designed specifically for medical and dental use. They include alumina, zirconia, bioactive glass, glass ceramics, hydroxyapatite, and calcium phosphates [7]. The classification of bioceramic materials into bioactive or bioinert materials is a function of their interaction with the surrounding living tissue [8]. Bioactive materials, such as glass and calcium phosphate, interact with the surrounding tissue to encourage the growth of more durable tissues [9]. Bioinert materials, such as zirconia and alumina, produce a negligible response from the surrounding tissue, effectively having no biological or physiological effect [8]. Bioactive materials are further classified according to their stability as degradable or nondegradable. Bioceramics are commonly used for orthopaedic treatments, such as joint or tissue replacements, and for coating metal implants to improve biocompatibility. Additionally, porous ceramics, such as calcium phosphate-based materials, have been used as bone graft substitutes [10].

Calcium phosphate was first used as bioceramic restorative dental cement by LeGeros et al. [11]. However, the first documented use of bioceramic materials as a root canal sealer was not until two years later when Krell and Wefel [12] compared the efficacy of experimental calcium phosphate cement with Grossman's sealer in extracted teeth, finding no significant difference between both sealers in terms of apical occlusion, adaptation, dentinal tubule occlusion, adhesion, cohesion, or morphological appearance. Nonetheless, the 
experimental calcium phosphate sealer failed to provide apical sealing as effectively as Grossman's sealer [13]. Chohayeb et al. [14] later evaluated the use of calcium phosphate as a root canal sealer in adult dog teeth. They reported that the calcium phosphate-based sealer made for a more uniform and tighter adaptation to the dentinal walls as compared to guttapercha [14]. Calcium phosphate cement has subsequently been used successfully in endodontic treatments, including pulp capping [15], apical barrier formation, periapical defect repairs [16], and bifurcation perforation repairs [17].

There are two major advantages associated with the use of bioceramic materials as root canal sealers. Firstly, their biocompatibility prevents rejection by the surrounding tissues [9]. Secondly, bioceramic materials contain calcium phosphate which enhances the setting properties of bioceramics and results in a chemical composition and crystalline structure similar to tooth and bone apatite materials [18], thereby improving sealer-to-root dentin bonding. However, one major disadvantage of these materials is in the difficulty in removing them from the root canal once they are set for later retreatment or post-space preparation [19].

The exact mechanism of bioceramic-based sealer bonding to root dentin is unknown; however, the following mechanisms have been suggested for calcium silicate-based sealers:

(1) Diffusion of the sealer particles into the dentinal tubules (tubular diffusion) to produce mechanical interlocking bonds [20].

(2) Infiltration of the sealer's mineral content into the intertubular dentin resulting in the establishment of a mineral infiltration zone produced after denaturing the collagen fibres with a strong alkaline sealer [21, 22].

(3) Partial reaction of phosphate with calcium silicate hydrogel and calcium hydroxide, produced through the reaction of calcium silicates in the presence of the dentin's moisture, resulting in the formation of hydroxyapatite along the mineral infiltration zone [23].

While various branded bioceramic-based root canal sealers are available on the market, others are still experimental, requiring further laboratory and clinical testing to ascertain their efficacy. A number of commercially available bioceramic-based root canal sealers, classified according to their major constituents, are identified in Table 1. The biological and physical properties of bioceramic-based root canal sealers were reviewed based on the ideal root canal sealer properties as described by Grossman [24], as in the following list:

(1) It should be tacky when mixed to provide good adhesion between it and the canal wall when set.

(2) It should make a hermetic seal.

(3) It should be radiopaque so that it can be visualized on the radiograph.

(4) The particles of powder should be very fine so that they can mix easily with liquid.

(5) It should not shrink upon setting.

(6) It should not discolour tooth structure.
(7) It should be bacteriostatic or at least not encourage bacterial growth.

(8) It should set slowly.

(9) It should be insoluble in tissue fluids.

(10) It should be well tolerated by the periapical tissue.

(11) It should be soluble in common solvents if it is necessary to remove the root canal filling.

\section{Ideal Root Canal Sealer Properties}

2.1. Biocompatibility. Biocompatibility is an essential requirement of any root canal sealer as the root filling material constitutes a true implant coming into direct contact with the vital tissue at the apical and lateral foramina of the root or indirectly via surface restoration [2]. Biocompatibility is defined as the ability of a material to achieve a proper and advantageous host response in specific applications [25]. In other words, a material is said to be biocompatible when the material coming into contact with the tissue fails to trigger an adverse reaction, such as toxicity, irritation, inflammation, allergy, or carcinogenicity [26]. Most studies assess biocompatibility through investigations of cytotoxicity, in reference to the effect of the material on cell survival [27]. The cytotoxicity of bioceramic-based sealers has been evaluated in vitro using mouse and human osteoblast cells [28, 29] and human periodontal ligaments cells [30]. Most bioceramicbased root canal sealers have subsequently been found to be biocompatible. This biocompatibility is attributed to the presence of calcium phosphate in the sealer itself. Calcium phosphate also happens to be the main inorganic component of the hard tissues (teeth and bone). Consequently, the literature notes that many bioceramic sealers have the potential to promote bone regeneration when unintentionally extruded through the apical foramen during root canal filling or repairs of root perforations [30, 31].

Sankin apatite has been shown by Telli et al. [32] to be biocompatible in in vitro studies. However, Kim et al. [33] showed that Sankin apatite exerts a tissue response when implanted subcutaneously in rats and that this response began to subside within two weeks. The biocompatibility of Sankin apatite root canal sealer was also evaluated in comparison to an experimental calcium phosphate-based sealer composed of tetracalcium phosphate, dicalcium phosphate dihydrate, and modified McIlvaine's buffer solution. Yoshikawa et al. [34] found that Sankin apatite caused severe inflammatory reactions in both the dorsal subcutaneous and the periapical tissue of rats. However, the experimental sealer produced no inflammatory response in the subcutaneous tissue and only a mild reaction in the periapical tissue [34]. The cytotoxicity of the Sankin apatite root canal sealer is the result of the presence of iodoform and polyacrylic acids in the sealer [33]. However, Sankin apatite type II and type III were found to be more biocompatible than either type I or Grossman's sealer [35]. EndoSequence BC, iRoot SP, and MTA-Fillapex showed moderate toxicity when freshly mixed; however, cytotoxicity reduced over time until being completely set $[29,36,37]$. Although in vitro evaluations of biocompatibility can be an indicator of the cytotoxicity 


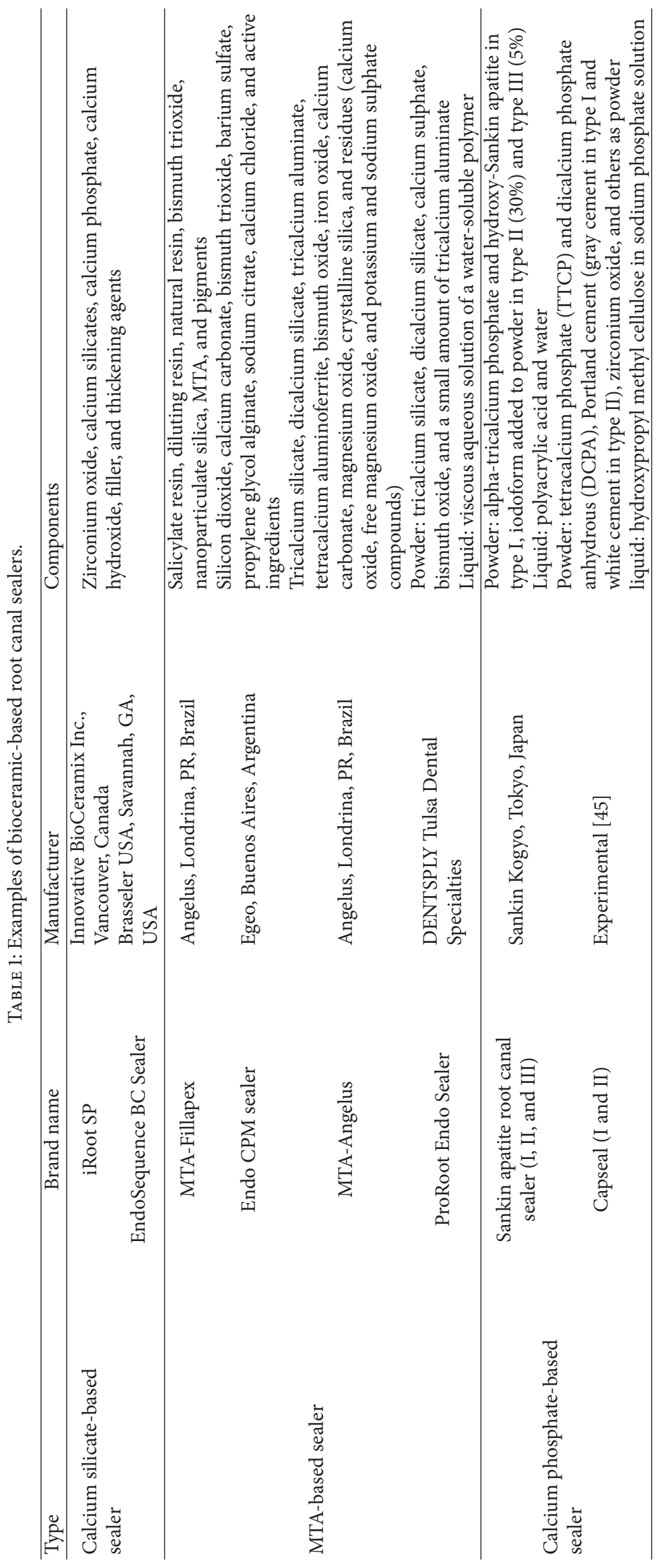


of a material, in vitro immunological deficiencies should be taken into consideration. Some sealers have been shown to have severe cytotoxicity in vitro, such as zinc oxide eugenolbased sealers; however, such toxicity is not necessarily clinically significant [38].

Capseal I and Capseal II sealers have been shown to produce less tissue irritation and less inflammation compared to other sealers [30, 31, 33]. Shon et al. [39] studied the effects of Capseal I and Capseal II in comparison to Sankin apatite root sealer (type I and type III) and a zinc oxide eugenol-based sealer (Pulp Canal Sealer). Investigators exposed human periodontal fibroblast cells to the various sealers before measuring the inflammatory response by way of inflammatory mediators and the viability and osteogenic potential of osteoblast MG63 cells. They found Capseal I and Capseal II to possess low cytotoxicity and to facilitate periapical dentoalveolar healing by regulating cellular mediators from periodontal ligaments cells and osteoblast differentiation. MTA-Fillapex was found to have a severe cytotoxic effect on fibroblast cells when freshly mixed. Furthermore, this effect did not decrease with time. The level of cytotoxicity remained moderate even five weeks after mixing [40].

2.2. Setting Time. The ideal root canal sealer setting time should permit adequate working time. However, a slow setting time can result in tissue irritation, with most root canal sealers producing some degree of toxicity until being completely set. According to the manufacturers of EndoSequence BC Sealer or iRoot SP, the setting reaction is catalysed by the presence of moisture in the dentinal tubules. While the normal setting time is four hours, in patients with particularly dry canals, the setting time might be considerably longer [41]. The amount of moisture present in the dentinal tubules of the canal walls can be affected by absorption with paper points [42], the presence of smear plugs, or tubular sclerosis [43].

Loushine et al. [28] reported that EndoSequence BC Sealer requires at least 168 hours before being completely set under different humidity conditions, as evaluated using the Gilmore needle method. Zhou et al. [44], on the other hand, reported a setting time of 2.7 hours. The setting reaction of EndoSequence BC Sealer is a two-phase reaction. In phase I, monobasic calcium phosphate reacts with calcium hydroxide in the presence of water to produce water and hydroxyapatite. In phase II, the water derived from the dentin humidity, as well as that produced by the phase I reaction, contributes to the hydration of calcium silicate particles to trigger a calcium silicate hydrate phase [28].

The manufacturer of MTA-Fillapex claims that their product will set in a minimum of two hours and this setting time has been confirmed in at least two studies [44, 51]. However, even shorter setting times for MTA-Fillapex (66 min) have been reported [52]. The setting reaction of MTA material is complicated and has been discussed by Darvell and Wu [53]; however, the setting reaction of MTA-based sealers has not been described in the literature.

2.3. Flow. Flow is an essential property that allows the sealer to fill difficult-to-access areas, such as the narrow irregularities of the dentin, isthmus, accessory canals, and voids between the master and accessory cones [54]. According to ISO 6786/2001 [55], a root canal sealer should have a flow rate of not less than $20 \mathrm{~mm}$. Factors that influence the flow rate of the sealer include particle size, temperature, shear rate, and time from mixing [4]. The internal diameter of the tubes and rate of insertion are considered when assessing flow rate via the Rheometer method [2]. The flow rate for EndoSequence BC Sealer has been variously reported as $23.1 \mathrm{~mm}$ and $26.96 \mathrm{~mm}[44,54]$. Similarly, the flow rate of MTAFillapex has been variously reported as $22 \mathrm{~mm}, 24.9 \mathrm{~mm}$, and $29.04 \mathrm{~mm}[44,51,52]$. While most of the bioceramicbased root sealer manufacturers included in Table 1 claim that the flow rate of their sealers meets ISO requirements, the literature does not support such claims.

2.4. Retreatability. Root filling materials provide a mechanical barrier for the isolation of necrotic tissue or bacteria responsible for the persistence of periapical inflammation or postoperative pain [56, 57]. Wilcox et al. [58] observe that most of the remaining material during retreatment is sealer. Therefore, the complete removal of the sealer is essential during endodontic retreatment to establish healthy periapical tissues. EndoSequence BC Sealer is difficult to remove from the root canal using conventional retreatment techniques, including heat, chloroform, rotary instruments, and hand files. A number of cases have been reported in which obstruction of the apical foramen has resulted in a loss of patency [59]. By contrast, Ersev et al. [60] reported that the removability of EndoSequence BC Sealer from the root canal is comparable to AH Plus. Sankin apatite root canal sealer is easily removed during retreatment with and without the use of solvents [61]. Retreatability with MTA-Fillapex is comparable to that of $\mathrm{AH}$ Plus in terms of material remaining in the canal, dentin removal, and time taken to reach working length [62].

2.5. Solubility. Solubility is the mass loss of a material during a period of immersion in water. According to ANSI/ADA Specification 57 [63], the solubility of a root canal sealer should not exceed $3 \%$ by mass. A highly soluble root canal sealer would invariably permit the formation of gaps within and between the material and the root dentin, thereby providing avenues for leakage from the oral cavity and periapical tissues [2].

Both iRoot SP and MTA-Fillapex are highly soluble, $20.64 \%$ and $14.89 \%$, respectively, which does not meet ANSI/ADA requirements $[52,64]$. This high solubility is the result of hydrophilic nanosized particles being present in both sealers which increases their surface area and allows more liquid molecules to come into contact with the sealer. However, the literature contains conflicting accounts, with Viapiana et al. [52] finding MTA-Fillapex to be highly soluble and Vitti et al. [51] reporting the solubility of MTA-Fillapex to be $<3 \%$, consistent with ISO $6876 / 2001$. Similarly, the solubility of EndoSequence BC is reported to be consistent with ISO 6876/2001 [44]. This discrepancy between the findings of these studies might be attributed to variations in the methods used to dry the samples after having subjected them to solubility testing. The low solubility of MTA-Angelus, 
consistent with ANSI/ADA requirements [64], is the result of an insoluble matrix of crystalline silica present within the sealer that maintains its integrity even in the presence of water [65].

2.6. Discolouration of Tooth Structure. For reasons of aesthetic appearance, a root canal sealer should not stain the tooth. The chromogenic effects of root sealers are increased when excess sealer is not removed from the coronal dentin of the pulp chamber [66]. Partovi et al. [67] observe that Sankin apatite III results in the least discolouration nine months after application as compared with AH26, Endofill, Tubli-Seal, and zinc oxide eugenol sealers. The greatest degree of discolouration was observed following treatment of the cervical third of the crown [67]. MTA-Fillapex was found to cause the least crown discolouration to the extent of not being clinically perceptible [66].

2.7. Radiopacity. Root canal sealers should be sufficiently radiopaque so as to be distinguishable from adjacent anatomical structures [68]. This allows the quality of the root filling to be evaluated through radiographic examination. According to ISO 6876/2001, the minimum radiopacity for a root canal sealer is based on a reference standard of $3.00 \mathrm{~mm}$ of aluminium. Candeiro et al. [54] reported the radiopacity of EndoSequence BC Sealer to be $3.83 \mathrm{~mm}$. Endo CPM sealer was found to have a radiopacity of $6 \mathrm{~mm}$ due to the presence of bismuth trioxide and barium sulphate [69]. Similarly, the presence of bismuth trioxide in MTA-Fillapex gives it a radiopacity of $7 \mathrm{~mm}[52,70]$.

2.8. Antimicrobial Properties. The antimicrobial activity of a root canal sealer increases the success rate of endodontic treatments by eliminating residual intraradicular infections that might have survived root canal treatment or have invaded the canal later through microleakage [71, 72]. According to the literature, the key antimicrobial properties of root canal sealers lie in their alkalinity and release of calcium ions [4] which stimulates repair via the deposition of mineralised tissue [73].

Two methods are commonly used to evaluate the antibacterial activity of bioceramic-based root canal sealers: the agar diffusion test [74, 75] and direct contact testing [23, 75]. EndoSequence BC Sealer has been shown to have high $\mathrm{pH}$ ( $>11)$ as well as high tendency to release calcium ions [54]. Zhang et al. [23] tested the antibacterial activity of iRoot SP sealer in vitro against Enterococcus faecalis through a modified direct contact test, finding that iRoot SP sealer had a high $\mathrm{pH}$ value (11.5) even after setting but that its antibacterial effect was greatly diminished after seven days. The investigators suggested two additional mechanisms associated with the antibacterial efficacy of iRoot SP: hydrophilicity and active calcium hydroxide diffusion [23]. Hydrophilicity reduces the contact angle of the sealer and facilitates penetration of the sealer into the fine areas of the root canal system to enhance the antibacterial effectiveness of iRoot SP in vivo [23].

Morgental et al. [75] evaluated the antibacterial activity of MTA-Fillapex and Endo CPM against Enterococcus faecalis using an agar diffusion test after mixing and a direct contact test after setting. The $\mathrm{pH}$ of the Endo CPM suspension was greater than that of MTA-Fillapex (>11); however, the bacterial inhibition zone produced by MTA-Fillapex was greater than that produced by Endo CPM [75]. The investigators attributed the antibacterial activity of MTA-Fillapex to the presence of resin as a core ingredient. Nevertheless, neither sealer was able to sustain its antibacterial activity after setting despite their initial high $\mathrm{pH}$ levels [75].

Enterococcus faecalis is the most common intraradicular microbe isolated from periapical periodontitis $[76,77]$ and is therefore commonly used to test the antibacterial activity of root canal sealers. Other microorganisms, such as Micrococcus luteus, Staphylococcus aureus, Escherichia coli, Pseudomonas aeruginosa, Candida albicans, and Streptococcus mutans, have also been used to test the antibacterial effects of bioceramic-based sealers [74, 78]. Freshly mixed Endo CPM exhibits antibacterial activity against Staphylococcus aureus and Streptococcus mutans with no significant reduction of the inhibition zone after setting. Nevertheless, the antibacterial effect is less than that of AH-26 [78]. MTA-Angelus has an antibacterial effect against Micrococcus luteus, Staphylococcus aureus, Escherichia coli, Pseudomonas aeruginosa, and Candida albicans [74].

2.9. Adhesion. Root canal sealer adhesion is defined as its capacity to adhere to the root canal dentin and promote GP cone adhesion to each other and the dentin [79]. Tagger et al. [80] argued that the term adhesion should be replaced with bonding in the case of root canal sealers because the attachment between the substances involves mechanical interlocking forces rather than molecular attraction. There is no standard method used to measure the adhesion of a sealer to the root dentin; therefore, the adhesion potential of the root filling material is commonly tested using microleakage and bond strength tests [81].

The sealing ability of a sealer is related to its solubility and to its bonding to the dentin and root canal filling cones [4]. Several studies have evaluated the sealing abilities of different bioceramic-based sealers in vitro. These studies are summarised in Table 2. Regardless of the different methodologies used, the sealing ability of bioceramic-based sealers has been found to be satisfactory and comparable to other commercially available sealers. However, until recently, there had been a paucity of literature concerning the longterm sealing ability or clinical outcomes associated with bioceramic-based sealers.

Bond strength is the force per unit area required to debond the adhesive material from the dentin [81]. Although no correlation has been identified between leakage and bond strength [82], the bond strength test has received significant attention due to the development of the "monoblock" concept in which a sealer bonds to both the core material and the dentinal wall to create a singular unit that enhances sealing and strengthens the root-filled tooth against fracture [83]. A strong bond between the root canal sealer and the root dentin is essential for maintaining the integrity of the sealer-dentin interface during the preparation of post-spaces and during tooth flexure [84]. Bioceramic-based sealers have the ability 


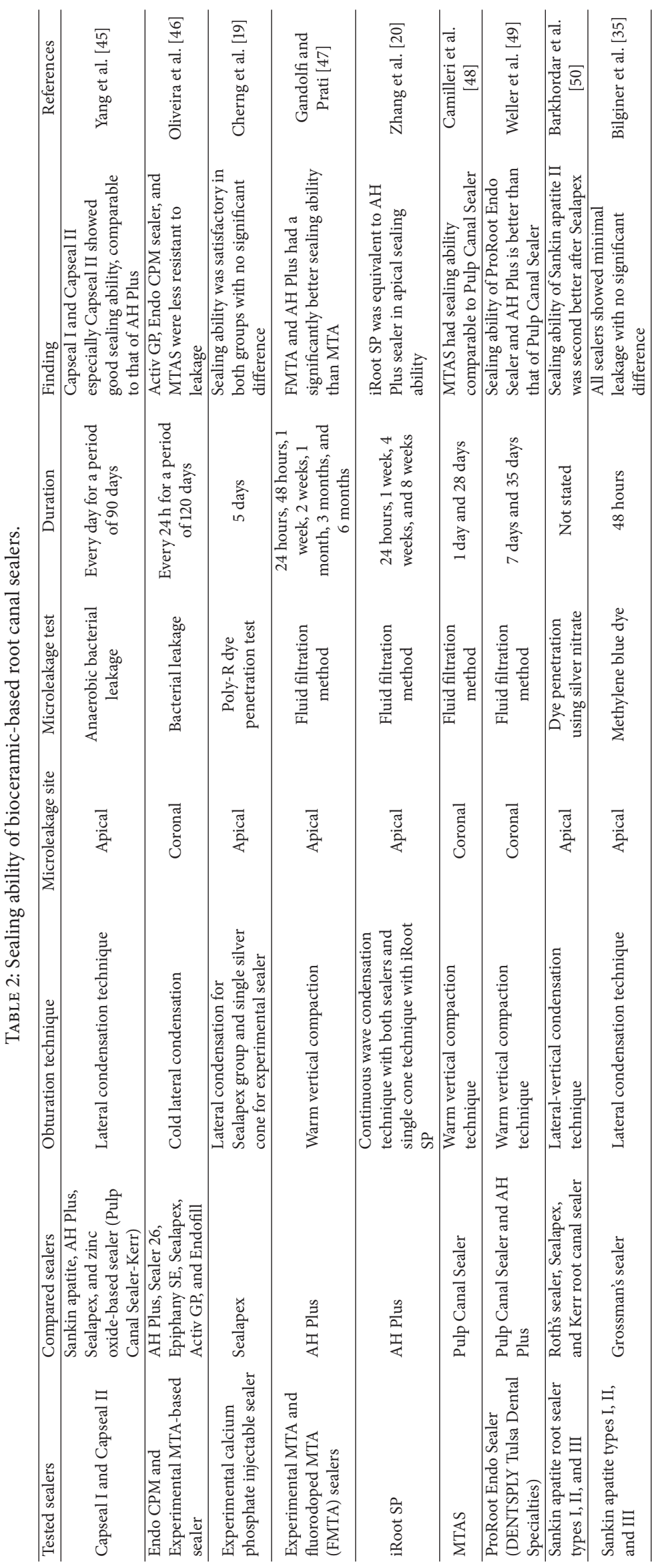


to create bonds between the dentin and core filling materials [9]. The bonding of iRoot SP to root dentin is comparable to that of $\mathrm{AH}$ Plus and stronger than either Sealapex or EndoREZ sealers [85]. Shokouhinejad et al. [86] evaluated the bond strength of EndoSequence BC Sealer compared to $\mathrm{AH}$ Plus in the presence and absence of a smear layer, finding that the dislocation resistance of EndoSequence $\mathrm{BC}$ Sealer was equal to that of AH Plus and with no significant effect on the smear layer. Nagas et al. [87] studied the bond strengths of several sealers under various moisture conditions present in the root canal, concluding that a sealer's bond strength is greatest in moist and wet canals, the presence of residual moisture positively affecting the adhesion of the root canal sealers to radicular dentin. As compared with AH Plus, Epiphany, and MTA-Fillapex, iRoot SP had the highest dislodgment resistance from the root dentin [87]. Moreover, the prior placement of intracanal calcium hydroxide improved the bonding of iRoot SP to the root dentin; however, the bonding was less than that of AH Plus and comparable to MTA-Fillapex in the absence of calcium hydroxide [88]. This improvement in bonding is explained by way of the chemical interaction between calcium hydroxide and the iRoot SP sealer increasing the frictional resistance and/or micromechanical retention of the sealer [88]. Endo CPM has a significantly higher bond strength compared to MTA-Fillapex or AH Plus [89].

Testing the bond strength at the coronal third of the root canal shows no significant difference between MTAFillapex, iRoot SP, and AH Plus. However, in middle and apical thirds, iRoot SP and AH Plus have equivalent bond strengths superior to MTA-Fillapex [90]. Huffman et al. [84] tested the dislocation resistance of ProRoot Endo Sealer, $\mathrm{AH}$ Plus Jet, and Pulp Canal Sealer from root dentin with and without immersion in a simulated body fluid (SBF). The investigators concluded that ProRoot Endo Sealer possesses greater bond strength than the other two sealers, especially after SBF immersion. According to Huffman et al. [84], the greater bonding of the ProRoot Endo Sealer is due to the presence of spherical amorphous calcium phosphate and apatite-like phases enhancing frictional resistance. There was no negative effect of the iRoot SP root canal sealer on the push-out bond strength of fibre posts cemented with selfadhesive resin cement [91]. Compared to Activ GP sealer (glass ionomer-based sealer, Brasseler USA, Savanah, GA), iRoot SP was found to increase the fracture resistance of endodontically treated roots in vitro, a potential indicator of the high bond strength of the sealer [92].

\section{Conclusion}

Bioceramic-based root canal sealers show promising results as root canal sealers. However, discrepancies in the results of these studies reveal that these sealers do not fulfil all of the requirements demanded of the ideal root sealer. The biocompatibility and biomineralization effect of these sealers might avail them for alternative uses in direct pulp capping and root end filling. Further studies are required to clarify the clinical outcomes associated with the use of these sealers.

\section{Competing Interests}

The authors declare that they have no competing interests.

\section{References}

[1] A. Kaur, N. Shah, A. Logani, and N. Mishra, "Biotoxicity of commonly used root canal sealers: a meta-analysis," Journal of Conservative Dentistry, vol. 18, no. 2, pp. 83-88, 2015.

[2] D. Orstavik, "Materials used for root canal obturation: technical, biological and clinical testing," Endodontic Topics, vol. 12, no. 1, pp. 25-38, 2005.

[3] K. Markowitz, M. Moynihan, M. Liu, and S. Kim, "Biologic properties of eugenol and zinc oxide-eugenol. A clinically oriented review," Oral Surgery, Oral Medicine, Oral Pathology, vol. 73, no. 6, pp. 729-737, 1992.

[4] S. Desai and N. Chandler, "Calcium hydroxide-based root canal sealers: a review," Journal of Endodontics, vol. 35, no. 4, pp. 475480, 2009.

[5] R. A. Buck, "Glass ionomer endodontic sealers-a literature review," General Dentistry, vol. 50, no. 4, pp. 365-368, 2002.

[6] Y. K. Kim, S. Grandini, J. M. Ames et al., "Critical review on methacrylate resin-based root canal sealers," Journal of Endodontics, vol. 36, no. 3, pp. 383-399, 2010.

[7] L. L. Hench, "Bioceramics: from concept to clinic," Journal of the American Ceramic Society, vol. 74, no. 7, pp. 1487-1510, 1991.

[8] S. M. Best, A. E. Porter, E. S. Thian, and J. Huang, "Bioceramics: past, present and for the future," Journal of the European Ceramic Society, vol. 28, no. 7, pp. 1319-1327, 2008.

[9] K. Koch and D. Brave, "A new day has dawned: the increased use of bioceramics in endodontics," Dentaltown, vol. 10, pp. 39-43, 2009.

[10] K. C. Saikia, T. D. Bhattacharya, S. K. Bhuyan, D. J. Talukdar, S. P. Saikia, and P. Jitesh, "Calcium phosphate ceramics as bone graft substitutes in filling bone tumor defects," Indian Journal of Orthopaedics, vol. 42, no. 2, pp. 169-172, 2008.

[11] R. LeGeros, A. Chohayeb, and A. Shulman, "Apatitic calcium phosphates: possible dental restorative materials," Journal of Dental Research, vol. 61, article 343, 1982.

[12] K. F. Krell and J. S. Wefel, "A calcium phosphate cement root canal sealer-scanning electron microscopic analysis," Journal of Endodontics, vol. 10, no. 12, pp. 571-576, 1984.

[13] K. V. Krell and S. Madison, "Comparison of apical leakage in teeth obturated with a calcium phosphate cement or Grossman's cement using lateral condensation," Journal of Endodontics, vol. 11, no. 8, pp. 336-339, 1985.

[14] A. A. Chohayeb, L. C. Chow, and P. J. Tsaknis, "Evaluation of calcium phosphate as a root canal sealer-filler material," Journal of Endodontics, vol. 13, no. 8, pp. 384-387, 1987.

[15] A. Jean, B. Kerebel, L.-M. Kerebel, R. Z. Legeros, and H. Hamel, "Effects of various calcium phosphate biomaterials on reparative dentin bridge formation," Journal of Endodontics, vol. 14, no. 2, pp. 83-87, 1988.

[16] E. Pissiotis and L. S. W. Spngberg, "Biological evaluation of collagen gels containing calcium hydroxide and hydroxyapatite," Journal of Endodontics, vol. 16, no. 10, pp. 468-473, 1990.

[17] J. Y. M. Chau, J. W. Hutter, T. O. Mork, and B. K. Nicoll, "An in vitro study of furcation perforation repair using calcium phosphate cement," Journal of Endodontics, vol. 23, no. 9, pp. 588-592, 1997. 
[18] M. P. Ginebra, E. Fernández, E. A. P. De Maeyer et al., "Setting reaction and hardening of an apatitic calcium phosphate cement," Journal of Dental Research, vol. 76, no. 4, pp. 905-912, 1997.

[19] A. M. Cherng, L. C. Chow, and S. Takagi, "In vitro evaluation of a calcium phosphate cement root canal filler/sealer," Journal of Endodontics, vol. 27, no. 10, pp. 613-615, 2001.

[20] W. Zhang, Z. Li, and B. Peng, "Assessment of a new root canal sealer's apical sealing ability," Oral Surgery, Oral Medicine, Oral Pathology, Oral Radiology and Endodontics, vol. 107, no. 6, pp. e79-e82, 2009.

[21] L. Han and T. Okiji, "Uptake of calcium and silicon released from calcium silicate-based endodontic materials into root canal dentine," International Endodontic Journal, vol. 44, no. 12, pp. 1081-1087, 2011.

[22] A. R. Atmeh, E. Z. Chong, G. Richard, F. Festy, and T. F. Watson, "Dentin-cement interfacial interaction: calcium silicates and polyalkenoates," Journal of Dental Research, vol. 91, no. 5, pp. 454-459, 2012.

[23] H. Zhang, Y. Shen, N. D. Ruse, and M. Haapasalo, "Antibacterial activity of endodontic sealers by modified direct contact test against Enterococcus faecalis," Journal of Endodontics, vol. 35, no. 7, pp. 1051-1055, 2009.

[24] L. Grossman, "Obturation of root canal," in Endodontic Practice, L. Grossman, Ed., p. 297, Lea and Febiger, Philadelphia, Pa, USA, 10th edition, 1982.

[25] D. F. Williams, Definitions in Biomaterials: Proceedings of a Consensus Conference of the European Society for Biomaterials, Chester, England, March 3-5, 1986, vol. 4 of Progress in Biomedical Engineering, Elsevier, Amsterdam, The Netherlands, 1987.

[26] Z. L. Sun, J. C. Wataha, and C. T. Hanks, "Effects of metal ions on osteoblast-like cell metabolism and differentiation," Journal of Biomedical Materials Research, vol. 34, no. 1, pp. 29-37, 1997.

[27] G. Schmalz, "Use of cell cultures for toxicity testing of dental materials-advantages and limitations," Journal of Dentistry, vol. 22, no. 2, pp. S6-S11, 1994.

[28] B. A. Loushine, T. E. Bryan, S. W. Looney et al., "Setting properties and cytotoxicity evaluation of a premixed bioceramic root canal sealer," Journal of Endodontics, vol. 37, no. 5, pp. 673677, 2011.

[29] L. P. Salles, A. L. Gomes-Cornélio, F. C. Guimarães et al., "Mineral trioxide aggregate-based endodontic sealer stimulates hydroxyapatite nucleation in human osteoblast-like cell culture," Journal of Endodontics, vol. 38, no. 7, pp. 971-976, 2012.

[30] W.-J. Bae, S.-W. Chang, S.-I. Lee, K.-Y. Kum, K.-S. Bae, and E.C. Kim, "Human periodontal ligament cell response to a newly developed calcium phosphate-based root canal sealer," Journal of Endodontics, vol. 36, no. 10, pp. 1658-1663, 2010.

[31] T. E. Bryan, K. Khechen, M. G. Brackett et al., "In vitro osteogenic potential of an experimental calcium silicate-based root canal sealer," Journal of Endodontics, vol. 36, no. 7, pp. 1163$1169,2010$.

[32] C. Telli, A. Serper, A. L. Dogan, and D. Guc, "Evaluation of the cytotoxicity of calcium phosphate root canal sealers by MTT assay," Journal of Endodontics, vol. 25, no. 12, pp. 811-813, 1999.

[33] J.-S. Kim, S.-H. Baek, and K.-S. Bae, "In vivo study on the biocompatibility of newly developed calcium phosphate-based root canal sealers," Journal of Endodontics, vol. 30, no. 10, pp. 708-711, 2004.

[34] M. Yoshikawa, S. Hayami, I. Tsuji, and T. Toda, "Histopathological study of a newly developed root canal sealer containing tetracalcium-dicalcium phosphates and $1.0 \%$ chondroitin sulfate," Journal of endodontics, vol. 23, no. 3, pp. 162-166, 1997.

[35] S. Bilginer, T. Esener, F. Söylemezoglu, and A. M. Tiftik, "The investigation of biocompatibility and apical microleakage of tricalcium phosphate based root canal sealers," Journal of Endodontics, vol. 23, no. 2, pp. 105-109, 1997.

[36] K. Zoufan, J. Jiang, T. Komabayashi, Y.-H. Wang, K. E. Safavi, and Q. Zhu, "Cytotoxicity evaluation of Gutta Flow and Endo Sequence BC sealers," Oral Surgery, Oral Medicine, Oral Pathology, Oral Radiology and Endodontology, vol. 112, no. 5, pp. 657661, 2011.

[37] D. Mukhtar-Fayyad, "Cytocompatibility of new bioceramicbased materials on human fibroblast cells (MRC-5)," Oral Surgery, Oral Medicine, Oral Pathology, Oral Radiology and Endodontology, vol. 112, no. 6, pp. e137-e142, 2011.

[38] T. P. Cotton, W. G. Schindler, S. A. Schwartz, W. R. Watson, and K. M. Hargreaves, "A retrospective study comparing clinical outcomes after obturation with Resilon/Epiphany or GuttaPercha/Kerr Sealer," Journal of Endodontics, vol. 34, no. 7, pp. 789-797, 2008.

[39] W.-J. Shon, K.-S. Bae, S.-H. Baek, K.-Y. Kum, A.-R. Han, and W.C. Lee, "Effects of calcium phosphate endodontic sealers on the behavior of human periodontal ligament fibroblasts and MG63 osteoblast-like cells," Journal of Biomedical Materials Research Part B: Applied Biomaterials, vol. 100, no. 8, pp. 2141-2147, 2012.

[40] E. J. Silva, C. C. Santos, and A. A. Zaia, "Long-term cytotoxic effects of contemporary root canal sealers," Journal of Applied Oral Science, vol. 21, no. 1, pp. 43-47, 2013.

[41] Q. Yang and D. Lu, "Premixed biological hydraulic cement paste composition and using the same," Google Patents, 2013.

[42] N. Hosoya, M. Nomura, A. Yoshikubo, T. Arai, J. Nakamura, and C. F. Cox, "Effect of canal drying methods on the apical seal," Journal of Endodontics, vol. 26, no. 5, pp. 292-294, 2000.

[43] F. Paqué, H. U. Luder, B. Sener, and M. Zehnder, “Tubular sclerosis rather than the smear layer impedes dye penetration into the dentine of endodontically instrumented root canals," International Endodontic Journal, vol. 39, no. 1, pp. 18-25, 2006.

[44] H.-M. Zhou, Y. Shen, W. Zheng, L. Li, Y.-F. Zheng, and M. Haapasalo, "Physical properties of 5 root canal sealers," Journal of Endodontics, vol. 39, no. 10, pp. 1281-1286, 2013.

[45] S.-E. Yang, S.-H. Baek, W. Lee, K.-Y. Kum, and K.-S. Bae, "In vitro evaluation of the sealing ability of newly developed calcium phosphate-based root canal sealer," Journal of Endodontics, vol. 33, pp. 978-981, 2007.

[46] A. C. M. Oliveira, J. M. G. Tanomaru, N. Faria-Junior, and M. Tanomaru-Filho, "Bacterial leakage in root canals filled with conventional and MTA-based sealers," International Endodontic Journal, vol. 44, no. 4, pp. 370-375, 2011.

[47] M. G. Gandolfi and C. Prati, "MTA and F-doped MTA cements used as sealers with warm gutta-percha. Long-term study of sealing ability," International Endodontic Journal, vol. 43, no. 10, pp. 889-901, 2010.

[48] J. Camilleri, M. G. Gandolfi, F. Siboni, and C. Prati, "Dynamic sealing ability of MTA root canal sealer," International Endodontic Journal, vol. 44, no. 1, pp. 9-20, 2011.

[49] R. N. Weller, K. C. Y. Tay, L. V. Garrett et al., "Microscopic appearance and apical seal of root canals filled with gutta-percha and ProRoot Endo Sealer after immersion in a phosphate-containing fluid," International Endodontic Journal, vol. 41, no. 11, pp. 977-986, 2008. 
[50] R. A. Barkhordar, M. M. Stark, and K. Soelberg, "Evaluation of the apical sealing ability of apatite root canal sealer," Quintessence International, vol. 23, no. 7, pp. 515-518, 1992.

[51] R. P. Vitti, C. Prati, E. J. N. L. Silva et al., "Physical properties of MTA fillapex sealer," Journal of Endodontics, vol. 39, no. 7, pp. 915-918, 2013.

[52] R. Viapiana, D. L. Flumignan, J. M. Guerreiro-Tanomaru, J. Camilleri, and M. Tanomaru-Filho, "Physicochemical and mechanical properties of zirconium oxide and niobium oxide modified Portland cement-based experimental endodontic sealers," International Endodontic Journal, vol. 47, no. 5, pp. 437448, 2014.

[53] B. W. Darvell and R. C. Wu, "MTA'-an hydraulic silicate cement: review update and setting reaction," Dental Materials, vol. 27, no. 5, pp. 407-422, 2011.

[54] G. T. D. M. Candeiro, F. C. Correia, M. A. H. Duarte, D. C. Ribeiro-Siqueira, and G. Gavini, "Evaluation of radiopacity, $\mathrm{pH}$, release of calcium ions, and flow of a bioceramic root canal sealer," Journal of Endodontics, vol. 38, no. 6, pp. 842-845, 2012.

[55] International Organization for Standardization, "Dental root canal sealing materials," ISO 6876, International Organization for Standardization, Geneva, Switzerland, 2001.

[56] L. R. Wilcox, "Endodontic retreatment: ultrasonics and chloroform as the final step in reinstrumentation," Journal of Endodontics, vol. 15, no. 3, pp. 125-128, 1989.

[57] J. F. Schirrmeister, K. T. Wrbas, K. M. Meyer, M. J. Altenburger, and E. Hellwig, "Efficacy of different rotary instruments for gutta-percha removal in root canal retreatment," Journal of Endodontics, vol. 32, pp. 469-472, 2006.

[58] L. R. Wilcox, K. V. Krell, S. Madison, and B. Rittman, "Endodontic retreatment: evaluation of gutta-percha and sealer removal and canal reinstrumentation," Journal of Endodontics, vol. 13, no. 9, pp. 453-457, 1987.

[59] D. Hess, E. Solomon, R. Spears, and J. He, "Retreatability of a bioceramic root canal sealing material," Journal of Endodontics, vol. 37, no. 11, pp. 1547-1549, 2011.

[60] H. Ersev, B. Yilmaz, M. E. Dinçol, and R. Dağlaroğlu, “The efficacy of ProTaper Universal rotary retreatment instrumentation to remove single gutta-percha cones cemented with several endodontic sealers," International Endodontic Journal, vol. 45, no. 8, pp. 756-762, 2012.

[61] A. Erdemir, N. Adanir, and S. Belli, "In vitro evaluation of the dissolving effect of solvents on root canal sealers," Journal of Oral Science, vol. 45, no. 3, pp. 123-126, 2003.

[62] P. Neelakantan, D. Grotra, and S. Sharma, "Retreatability of 2 mineral trioxide aggregate-based root canal sealers: a conebeam computed tomography analysis," Journal of Endodontics, vol. 39, no. 7, pp. 893-896, 2013.

[63] ANSI/ADA, Specification No 57 Endodontic Sealing Material, ADA Publishing, Chicago, Ill, USA, 2000.

[64] R. P. Borges, M. D. Sousa-Neto, M. A. Versiani et al., "Changes in the surface of four calcium silicate-containing endodontic materials and an epoxy resin-based sealer after a solubility test," International Endodontic Journal, vol. 45, no. 5, pp. 419-428, 2012.

[65] M. Fridland and R. Rosado, "Mineral trioxide aggregate (MTA) solubility and porosity with different water-to-powder ratios," Journal of Endodontics, vol. 29, no. 12, pp. 814-817, 2003.

[66] K. Ioannidis, I. Mistakidis, P. Beltes, and V. Karagiannis, "Spectrophotometric analysis of crown discoloration induced by MTA- and ZnOE-based sealers," Journal of Applied Oral Science, vol. 21, no. 2, pp. 138-144, 2013.
[67] M. Partovi, A. H. Al-Havvaz, and B. Soleimani, "In vitro computer analysis of crown discolouration from commonly used endodontic sealers," Australian Endodontic Journal, vol. 32, no. 3, pp. 116-119, 2006.

[68] Y. Imai and T. Komabayashi, "Properties of a new injectable type of root canal filling resin with adhesiveness to dentin," Journal of Endodontics, vol. 29, no. 1, pp. 20-23, 2003.

[69] J. M. Guerreiro-Tanomaru, M. A. H. Duarte, M. Gonçalves, and M. Tanomaru-Filho, "Radiopacity evaluation of root canal sealers containing calcium hydroxide and MTA," Brazilian Oral Research, vol. 23, no. 2, pp. 119-123, 2009.

[70] E. J. N. L. Silva, T. P. Rosa, D. R. Herrera, R. C. Jacinto, B. P. F. A. Gomes, and A. A. Zaia, "Evaluation of cytotoxicity and physicochemical properties of calcium silicate-based endodontic sealer MTA fillapex," Journal of Endodontics, vol. 39, no. 2, pp. 274-277, 2013.

[71] G. S. P. Cheung, "Endodontic failures-changing the approach," International Dental Journal, vol. 46, no. 3, pp. 131-138, 1996.

[72] U. Sjögren, D. Figdor, S. Persson, and G. Sundqvist, "Influence of infection at the time of root filling on the outcome of endodontic treatment of teeth with apical periodontitis," International Endodontic Journal, vol. 30, no. 5, pp. 297-306, 1997.

[73] T. Okabe, M. Sakamoto, H. Takeuchi, and K. Matsushima, "Effects of $\mathrm{pH}$ on mineralization ability of human dental pulp cells," Journal of Endodontics, vol. 32, no. 3, pp. 198-201, 2006.

[74] M. Tanomaru-Filho, J. M. G. Tanomaru, D. B. Barros, E. Watanabe, and I. Y. Ito, "In vitro antimicrobial activity of endodontic sealers, MTA-based cements and Portland cement," Journal of Oral Science, vol. 49, no. 1, pp. 41-45, 2007.

[75] R. D. Morgental, F. V. Vier-Pelisser, S. D. Oliveira, F. C. Antunes, D. M. Cogo, and P. M. P. Kopper, "Antibacterial activity of two MTA-based root canal sealers," International Endodontic Journal, vol. 44, no. 12, pp. 1128-1133, 2011.

[76] E. T. Pinheiro, B. P. F. A. Gomes, C. C. R. Ferraz, E. L. R. Sousa, F. B. Teixeira, and F. J. Souza-Filho, "Microorganisms from canals of root-filled teeth with periapical lesions," International Endodontic Journal, vol. 36, no. 1, pp. 1-11, 2003.

[77] C. H. Stuart, S. A. Schwartz, T. J. Beeson, and C. B. Owatz, "Enterococcus faecalis: its role in root canal treatment failure and current concepts in retreatment," Journal of Endodontics, vol. 32, no. 2, pp. 93-98, 2006.

[78] Z. Mohammadi, L. Giardino, F. Palazzi, and S. Shalavi, "Antibacterial activity of a new mineral trioxide aggregate-based root canal sealer," International Dental Journal, vol. 62, no. 2, pp. 7073, 2012.

[79] M. D. Sousa-Neto, F. I. Silva Coelho, M. A. Marchesan, E. Alfredo, and Y. T. C. Silva-Sousa, "Ex vivo study of the adhesion of an epoxy-based sealer to human dentine submitted to irradiation with Er: YAG and Nd: YAG lasers," International Endodontic Journal, vol. 38, no. 12, pp. 866-870, 2005.

[80] M. Tagger, E. Tagger, A. H. L. Tjan, and L. K. Bakland, "Measurement of adhesion of endodontic sealers to dentin," Journal of Endodontics, vol. 28, no. 5, pp. 351-354, 2002.

[81] R. S. Schwartz, "Adhesive dentistry and endodontics. Part 2: bonding in the root canal system-the promise and the problems: a review," Journal of Endodontics, vol. 32, no. 12, pp. 1125-1134, 2006.

[82] A. Wennberg and D. Orstavik, "Adhesion of root canal sealers to bovine dentine and gutta-percha," International Endodontic Journal, vol. 23, no. 1, pp. 13-19, 1990. 
[83] F. B. Teixeira, E. C. N. Teixeira, J. Y. Thompson, and M. Trope, "Fracture resistance of roots endodontically treated with a new resin filling material," Journal of the American Dental Association, vol. 135, no. 5, pp. 646-652, 2004.

[84] B. Huffman, S. Mai, L. Pinna et al., "Dislocation resistance of ProRoot Endo Sealer, a calcium silicate-based root canal sealer, from radicular dentine," International Endodontic Journal, vol. 42, no. 1, pp. 34-46, 2009.

[85] S. Ersahan and C. Aydin, "Dislocation resistance of iRoot SP, a calcium silicate-based sealer, from radicular dentine," Journal of Endodontics, vol. 36, no. 12, pp. 2000-2002, 2010.

[86] N. Shokouhinejad, H. Gorjestani, A. A. Nasseh, A. Hoseini, M. Mohammadi, and A. R. Shamshiri, "Push-out bond strength of gutta-percha with a new bioceramic sealer in the presence or absence of smear layer," Australian Endodontic Journal, vol. 39, no. 3, pp. 102-106, 2013.

[87] E. Nagas, M. O. Uyanik, A. Eymirli et al., "Dentin moisture conditions affect the adhesion of root canal sealers," Journal of Endodontics, vol. 38, no. 2, pp. 240-244, 2012.

[88] S. A. Wanees Amin, R. S. Seyam, and M. A. El-Samman, "The effect of prior calcium hydroxide intracanal placement on the bond strength of two calcium silicate-based and an epoxy resinbased endodontic sealer," Journal of Endodontics, vol. 38, pp. 696-699, 2012.

[89] E. Assmann, R. K. Scarparo, D. E. Böttcher, and F. S. Grecca, "Dentin bond strength of two mineral trioxide aggregate-based and one epoxy resin-based sealers," Journal of Endodontics, vol. 38, no. 2, pp. 219-221, 2012.

[90] B. Sagsen, Y. Ustün, S. Demirbuga, and K. Pala, "Push-out bond strength of two new calcium silicate-based endodontic sealers to root canal dentine," International Endodontic Journal, vol. 44, no. 12, pp. 1088-1091, 2011.

[91] E. Özcan, İ. Çapar, A. R. Çetin, A. R. Tunçdemir, and H. A. Aydinbelge, "The effect of calcium silicate-based sealer on the push-out bond strength of fibre posts," Australian Dental Journal, vol. 57, no. 2, pp. 166-170, 2012.

[92] A. G. Ghoneim, R. A. Lutfy, N. E. Sabet, and D. M. Fayyad, "Resistance to fracture of roots obturated with novel canalfilling systems," Journal of Endodontics, vol. 37, no. 11, pp. 15901592, 2011. 

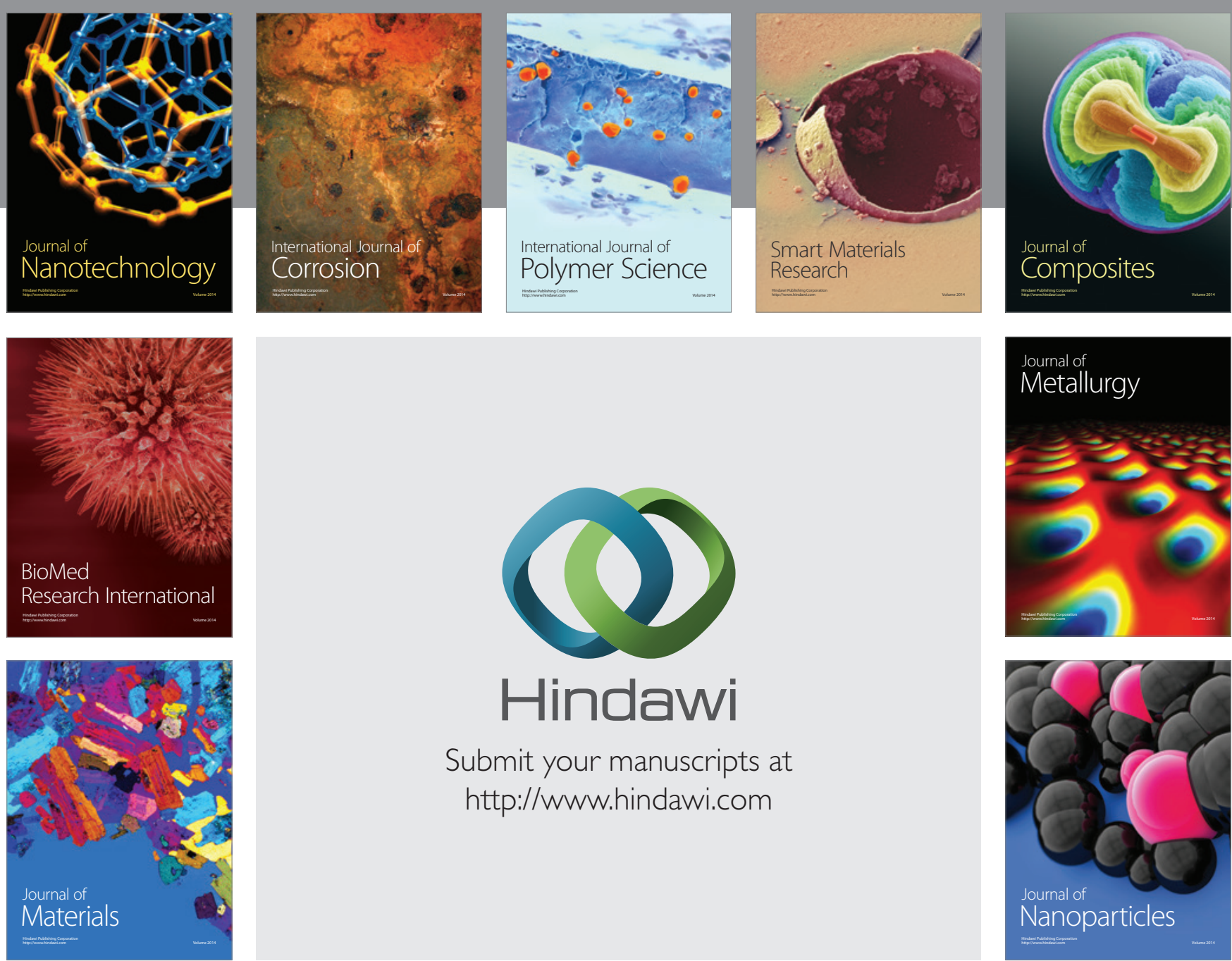

\section{Hindawi}

Submit your manuscripts at

http://www.hindawi.com

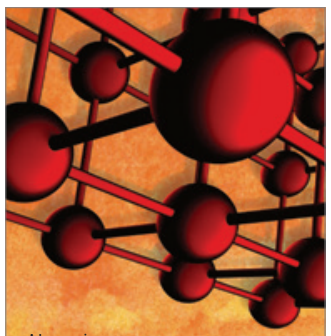

Materials Science and Engineering
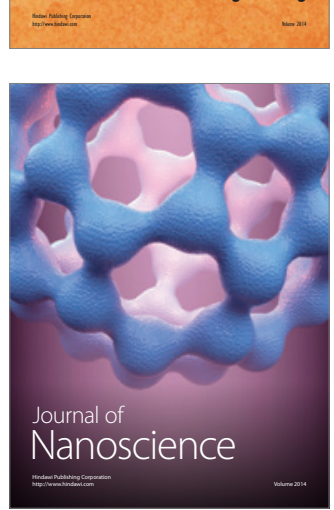
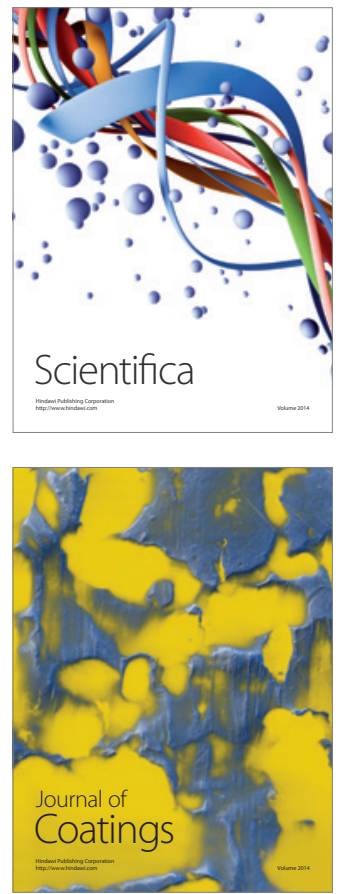
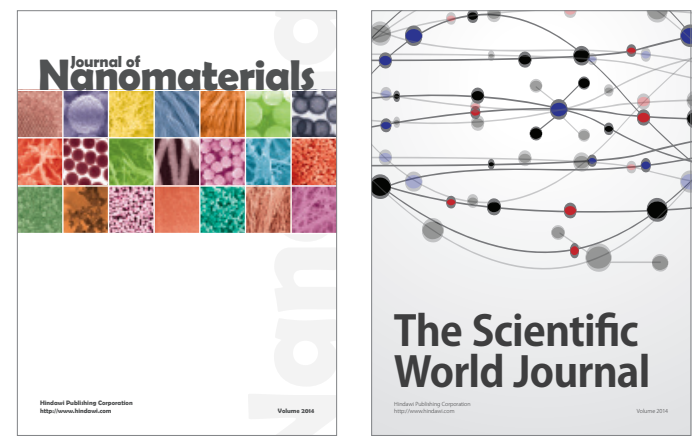

The Scientific World Journal
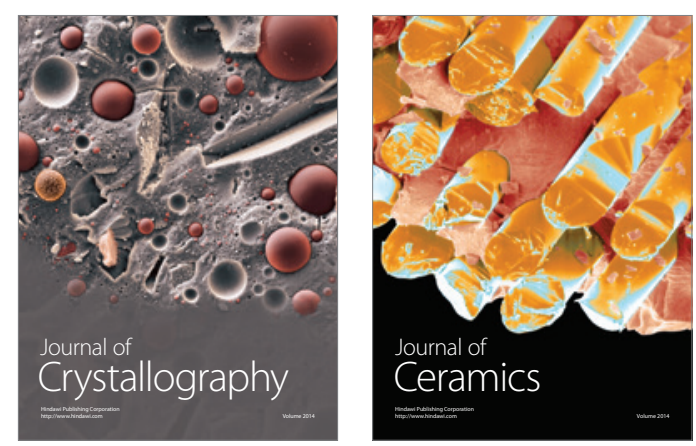
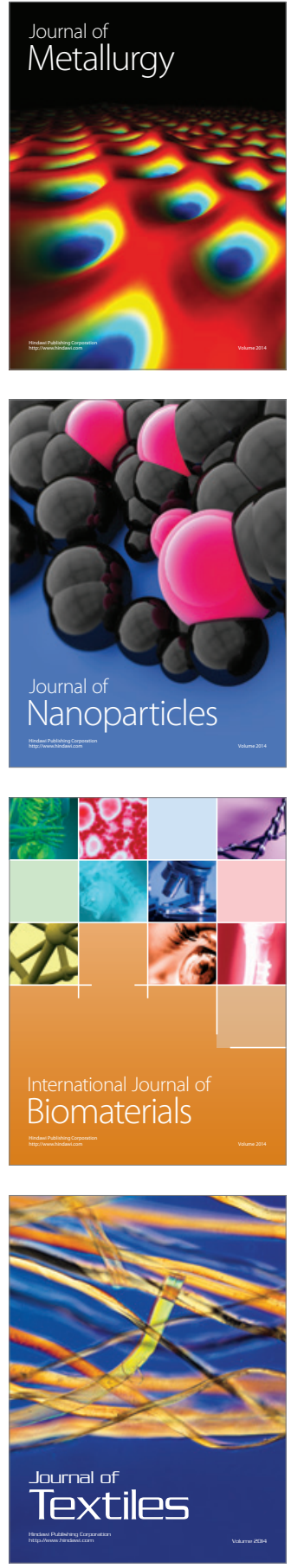